\title{
Increased fetal loss in women with heritable thrombophilia
}

\author{
FEPreston FR Rosendaal ID Walker E Briet E Berntorp J Conard J Fontcuberta M Makris G Marianı \\ W Noteboom I Pabinger C Legnanı I Scharrer S Schulman F J M van der Meer
}

\begin{abstract}
Summary
Background A successful outcome of pregnancy requires an efficient uteroplacental vascular system Since this system may be compromised by disorders of haemostasis associated with a prothrombotic state we postulated that maternal thrombophilia might be a risk factor for fetal loss We studied the relation between heritable thrombophilic defects and fetal loss in a cohort of women with factor $V$ Leiden or deficiency of antithrombin protein $C$ or protein $S$
\end{abstract}

Methods We studied 1384 women enrolled in the European Prospective Cohort on Thrombophilla (EPCOT) Of 843 women with thrombophila 571 had 1524 pregnancies of 541 control women 395 had 1019 pregnancies The controls were partners of male members of the EPCOT cohort or acqualntances of cases $W e$ analysed the frequencies of miscarriage (fetal loss at or before 28 weeks of gestation) and stillbirth (fetal loss after 28 weeks of gestation) jointly and separately

Findings The risk of fetal loss was increased in women with thrombophilia (168/571 vs 93/395 odds ratio 135 [95\% Cl 1 01-1 82]) The odds ratio was higher for stillbirth than for miscarriage ( 36 [1 4-9 4] vs 127 [0 94-1 71]) The highest odds ratio for stillbirth was in women with combined defects (143 [2 4-86 0]) compared with 52 (15-18 1) in antithrombin deficiency $23(06-83)$ in protein $C$ deficiency $33(10-113)$ in protein $S$ deficiency and $20(05-77)$ with factor $V$ Leiden The corresponding odds ratios for miscarriage in these subgroups were 08 (0 2-3 6) $17(10-28) 14(09-22) 12(07-19)$ and 09 (05-15) Significantly more pregnancy terminations had been done in women with thrombophilia than in controls (odds ratıo 29 [1 8-4 8]) this discrepancy was apparent in nıne of 11 participatıng centres and for all thrombophilia subgroups

Interpretation Women with familial thrombophilia especially those with combined defects or antithrombın

Royal Hallamshure Hospıtal, Sheffield UK (Prof F E Preston MD M Makris MD), University Hospital, Leiden, Netherlands (F R Rosendaal MD W Noteboom F J M van der Meer MD), Royal Infirmary, Glasgow, UK (I D Walker MO), Academıc Medıcal Center, Amsterdam, Netherlands (E Briet MD), Lund University, Malmo, Sweden (E Berntorp MD), Hotel Dieu de Parıs France ( Conard MD), Hospital de la Santa Creu dı Sant Pau Barcelona, Spain (J Fontcuberta MD), La Sapıenza University, Rome, Italy (G Marıanı MD), Allgemeınes Krankenhaus der Stadt Wien, Vienna, Austria (I Pabinger MD), University Hospital S Orsola Bologna, Italy (C Legnanı BSc), Klınıkum der J W Goethe Universıtat Frankfurt am Maın, Germany (I Scharrer $M D$ ), and National Haemophilia Centre, Tel Hashomer, Israel ( $S$ Schulman MD)

Correspondence to DrFR Rosendaal Department of Clinıcal Epidemiology and Haematology Bldg 1 COP University Hospital Leiden PO Box 9600 NL 2300 RC Leiden Netheriands deficiency have an increased risk of fetal loss particularly stillirith Our findings have important implications for therapy and provide a rationale for clinical trials of thromboprophylaxis for affected women with recurrent fetal loss

Lancet 1996 348. 913-16

\section{Introduction}

Until lately, a clear relation with a genetic thrombophilic defect was evident in only $5-10 \%$ of patients presenting with venous thromboembolism and was confined to those with deficiencies of antithrombin, protein $C$, and protein $S$ The importance of heritable defects as risk factors for venous thromboembolism has increased with the discovery of a genetic thrombophilic disorder that manifests as resistance to activated protein $C(A P C)^{1}$ and the observation that this disorder is present in about $20 \%$ of individuals presenting with venous thrombosis Bertina and colleagues ${ }^{3}$ have shown that in most indir iduals APC resistance is the result of a single point mutation in the factor $\mathrm{V}$ gene at nucleotide 1691, which codes for the APC cleavage site (factor V Leiden mutation) In much of Europe and in the USA the prevalence of the factor $\mathrm{V}$ Leiden defect is $3-5 \%$ However, in other parts of the world, such as southeast Asia and Afica, the prevalence of the defect is less than $1 \%$ *

In pregnancy, a successful outcome is highlv dependent on satusfactory placental development and sustamed placental function These processes, in turn, require the establishment of an adequate fetomaternal circulator system Since this system may be compromised bv disturbances of haemostasis leading to a prothrombotic state, we postulated that maternal thrombophilia might be a risk factor for fetal loss We have therefore studied the relation between heritable thrombophilic detects and fetal loss in a cohort of women who have factor $V$ Leiden or deficiencies of antithrombin, protein $C$, or protein $S$ (the European Prospective Cohort on Thrombophilia [EPCOT]) and in a control group Although EPCOT is i prospective follow-up study, the data here were collected at baseline and give information on lifetime occurrence of miscarriage and stillbirth

\section{Patients and methods}

The women described here were cnrolled in LPCOT betricen Janu ury, 1994, and November 1995 The primu um of the study is to establish the risk of thrombosis in this sroup it disorders A sccondary aim is to imestig ate the possible relition between these disorders and the rish of tec 11 loss

The index group consists of mile and lem le indiudulds of all ages with or without symptomite dise ise Lich puticupitin. contre cnrolled all registered piticnts who hid hercdicus thrombophine clused by deficiencics of proten ( peotem $s$ a 


\begin{tabular}{|c|c|c|c|c|c|c|c|}
\hline & \multicolumn{3}{|l|}{ Deflclencles of } & \multirow{2}{*}{$\begin{array}{l}\text { Factor V } \\
\text { Leiden }\end{array}$} & \multirow{2}{*}{$\begin{array}{l}\text { Combined } \\
\text { defects * }\end{array}$} & \multirow[t]{2}{*}{ All patients } & \multirow[t]{2}{*}{ Controls } \\
\hline & Antithrombin & Protein C & Proteln $S$ & & & & \\
\hline Women ever pregnant & 108 & 162 & 145 & 141 & 15 & 571 & 395 \\
\hline Number of pregnancies & 260 & 430 & 378 & 410 & 46 & 1.524 & 1019 \\
\hline $\begin{array}{l}\text { Number of pregnancies } \\
\text { ending in miscarriage }\end{array}$ & $44(169 \%)$ & $68(158 \%)$ & $55(146 \%)$ & $43(105 \%)$ & $6(13 \%)$ & $216(142 \%)$ & $118(116 \%)$ \\
\hline $\begin{array}{l}\text { Number of pregnancies } \\
\text { ending in st libirth }\end{array}$ & $6(23 \%)$ & $5(12 \%)$ & $7(19 \%)$ & $5(12 \%)$ & $7(15 \%)$ & $30(20 \%)$ & $6(06 \%)$ \\
\hline $\begin{array}{l}\text { Number of women with } \\
\text { fetal loss }{ }^{\dagger}\end{array}$ & $34(315 \%)$ & $48(296 \%)$ & $42(290 \%)$ & $38(269 \%)$ & $6(40 \%)$ & $168(294 \%)$ & $93(235 \%)$ \\
\hline $\begin{array}{l}\text { Number of pregnanc es } \\
\text { resulting n fetal loss }{ }^{-}\end{array}$ & $50(192 \%)$ & $73(170 \%)$ & $62(164 \%)$ & $48(117 \%)$ & $13(28 \%)$ & $246(161 \%)$ & $124(122 \%)$ \\
\hline
\end{tabular}

*4 protein $C$ deficiency+factor $V$ Leiden 7 protein $S$ deficiency+factor $V$ Leiden 2 antithrombin deficiency+factor $V$ Leiden and 2 protein $C$ and protein $S$ deficiencies tExcludes terminations of pregnancy

Table 1 Number of pregnancies and fetal loss

antithrombin, or by factor $\mathrm{V}$ Leiden There were no exclusion criteria Healthy controls are enrolled in the studv for reasons of comparison The patients were asked whether their spouses (or partners) would be willing to serve as controls Single patients were asked to find an acquaintance who would be willing to serve as a control We left the patient to decide whether the control was of the same sex or not Since the controls are partners $(65 \%)$ or acquaintances $(35 \%)$ of the index individuals, the control group is of about the same age as the index group We excluded from the control group blood relatives of the index patient and individuals known to have familial thrombophilia All data collection, at baseline, and at follow-up was the same for the patients and controls We report here the data collected at baseline, referring to events before entry to EPCOT

Before study enrolment, informed consent was obtained from all individuals, including controls Data were collected at entry to the study and annually thereafter, by questionnaire or by telephone or personal interview Data recorded include general demographic information, thrombosis history, medication, risk factors for thrombosis, family history, obstetric history, and detals on type and subtype of thrombophilia Standard datacollection forms are used at all participating centres For each patient, the diagnosis of heritable thrombophilia is confirmed by the diagnostic criteria of the study protocol All contributing centres participate in an external quality-assessment scheme for thrombophilia testing

We calculated the number of women in each group who had been pregnant and analysed the outcome of all pregnanciesmiscarriage, pregnancy termination, stillbirth, or livebirth Miscarriage was defined as fetal loss during the first or second trimester (1e, up to and including 28 weeks' gestation) Stillbirth was defined as intrauterine death during the third trimester (1e, after 28 weeks' gestation) We could obtain information only on known or confirmed pregnancies We assessed differences in the rish of fetal loss by companing the number of women who had ever experienced miscarriage or stillbirth by cross-tabulation and $\chi$ test We also compared the frequencies of pregnancy termination between the groups

The structure of the control group made study of the effect of paternal thrombophilia on fetal loss possible For this report only the women from EPCOT are included as patients, and the controls are female partners of thrombophilic men, or unrelated acquantances of thrombophinc patients By comparing the frequency of tetal loss in control women who are partners of thrombophilic men and those who are not, we investigated the effect of paternal thrombophila on miscarrage and stillbirth

The mean number of pregnanctes differed among the various study groups, this difference had to be taken into account since the rish of fetal loss obviously increases with the number of pregnincies We therefote carried out logistic regression analysis with ever-experience of tetal loss as the outcome (dependent) variable and the total number of pregnancies as one of the covulutcs (independent varable) When a varable of intercst is included in the model (for example, whether a woman is a thiombophilic patiunt or a control), this regression analysis will produce an odds ratio tor that varuble This odds ratio is a measure of relative risk, and is the ratio of the odds of tetal loss in an index woman over the odds in a control woman, adjusted for the number of pregnancies An odds ratio of more than one indicates a risk exceeding that of controls As a variable of interest we also looked at the type of thrombophlia, a dumny variable model gave separate odds ratios, each compared with the controls, for each subtvpe of thrombophilia Since the participating centres are spread widely across Europe, and since we investıgated lifetume risk of fetal loss and our study period encompassed several decades, we also assessed the effect of adjustment for possible regional and time effects, by adding centre (as a dummy variable) and current age (as a continuous term) into the models used Since adjustment for age did not lead to any change, this variable was omitted from the models presented We then investigated the effect of thrombophilia on miscarnage and stillbirth separately To allow for the possibility that heterogeneity among women in other, unknown, factors might affect the risk of fetal loss, we also analysed the risk of pregnancies ending in fetal loss by a random effects model

\section{Results}

Patients and controls were enrolled by 11 centres from nine countries (Le1den, Barcelona, Bologna, Frankfurt, Glasgow, Malmo, Paris, Rome, Sheffield, Tel-Hashomer, Vienna) On Nov 1, 1995, 1384 women had been enrolled (843 patients, 541 controls) Most of the controls (354 [65\%]) were partners of index patients, this proportion was $79 \%$ (311/395) among the controls who had been pregnant at least once The patients were 242 women with protein-C deficiency, 214 with proten-S deficiency, 159 with antithrombin deficiency, 203 with the factor $V$ Leiden defect, and 25 with combined defects 571 patients had had 1524 pregnancies compared with 1019 pregnancies in 395 controls

Here we report on fetal loss among women who had been pregnant at least once (571 patients-162 with protein-C deficiencv, 145 with protein-S deficiency, 108 with antithrombin deficiency, 141 with the factor $\mathrm{V}$ Leiden defect, and 15 with combined defects) The mean age of the 966 women who had been pregnant at least once (571 patients, 395 controls) at enrolment was 462 years (range 20-92), the mean age was similar for patients and controls (mean 457 [SD 13 8] vs 470 [12 2] years) The number of pregnancies ranged from 1 to 14 (patients 1-14, controls 1-11) and the number of fetal losses per

\begin{tabular}{|c|c|c|c|}
\hline & $\begin{array}{l}\text { Patlents } \\
(n=571)\end{array}$ & $\begin{array}{l}\text { Controis } \\
(n=395)\end{array}$ & Odds ratio $(95 \% \mathrm{Cl})$ \\
\hline Any fetal loss & 168 & 93 & $135(101-182)$ \\
\hline Miscarriage & 154 & 89 & $127(094-171)$ \\
\hline St.llburth & 25 & 5 & $36(14-94)$ \\
\hline
\end{tabular}

Numbers of miscarrages and stulibirths do not add up to the numbers under any fet al loss or overall figures in table 1 since some women have experienced miscarriages and stillberths

Table 2 Odds ratios of fetal loss in women with thrombophilıa 


\begin{tabular}{|c|c|c|c|}
\hline Type & $\begin{array}{l}\text { All spontaneous } \\
\text { fetal losses }\end{array}$ & Mlscarriage & Stlllblrth \\
\hline Antithrombin deficiency & $21(12-36)$ & $17(1028)$ & $52(15-181)$ \\
\hline Prote $n \mathrm{C}$ deficiency & $14(09-22)$ & $14(09-22)$ & $23(06-83)$ \\
\hline Protein $\$$ deficiency & $13(08-21)$ & $12(07-19)$ & $33\left(\begin{array}{llll}1 & 0 & 11 & 3\end{array}\right)$ \\
\hline Factor $V$ Le den & $10(06-17)$ & $09(0515)$ & $20(05-77)$ \\
\hline Combined defects & $20(05-81)$ & $08(02-36)$ & $143(24-860)$ \\
\hline
\end{tabular}

Table 3 Odds ratios $(95 \% \mathrm{CI})$ for fetal loss and type of thrombophilia, with control group as reference, adjusted for number of pregnancies and centre

woman ranged from 0 to 6 in both groups The mean number of pregnancies was similar in patients and controls (27 [ [ 1 7] vs 26 [1 4])

\section{Fetal loss}

Significantly more women with thrombophilia than controls had experienced fetal loss (miscarriage or stillbirth, table $1, p=0$ 04) The odds ratio for fetal loss associated with thrombophila was 135 (95\% CI 1 01-1 82) Random effects modelling led to a very simular result (1 40 [1 04-1 90]) The percentage of pregnancies ending in fetal loss (with terminations of pregnancy excluded) was significantly greater in each of the subgroups of patients with deficiencies of antithrombin, protein $C$, or protein $S$ and in the subgroup with combined defects than in the control group The percentage of pregnancies ending in fetal loss in women with factor $V$ Lexden did not differ significantly from that in the control group

For all women with thrombophilia compared with controls the relative risk of stillbirth was greater than that for miscarriage (table 2)

We carried out logistic regression to adjust the risk of fetal loss in thrombophilia for differences in the number of pregnancies Table 3 shows the odds ratios for both stillbirths and miscarriages for women with each type of thrombophlia and for those with combined defects, with the control group as reference, adjusted for the number of pregnancies and centre Further adjustment for age did not affect the estimates The random effects model gave essentially the same coefficients as the fixed model The odds of ever having had a spontaneous fetal loss were $30-36 \%$ greater in women with deficiencies of protein $\mathrm{C}$ or protein $S$ than in controls without thrombophilia and $200 \%$ higher in women with antithrombin deficiency or with combined defects than in controls After we had adjusted for the higher number of pregnancies in carriers of factor $\mathrm{V}$ Leiden, we no longer found an excess nsk of fetal loss associated with this abnormality (odds ratio 10 [0 6-1 7])

We repeated the multivariate analysis for miscarriages and stillbirths as scparate outcomes, adjusted for the number of pregnancies This analysis confirmed the more pronounced odds ratıo for stillbirths than for miscarriages

\begin{tabular}{|c|c|c|}
\hline & \multicolumn{2}{|c|}{$\%$ of women with pregnancies ending in fetal loss } \\
\hline & Terminations inclided & Termınations excluded \\
\hline \multicolumn{3}{|l|}{ Thrombophilic subgroup } \\
\hline Ant thro nuin deficiency & 491 & 315 \\
\hline Protem C defictency & 383 & 296 \\
\hline Proten $S$ deficlency & 407 & 290 \\
\hline Factor V Leiden & 376 & 269 \\
\hline Combined difects & 467 & 400 \\
\hline Controls & 286 & 235 \\
\hline
\end{tabular}

Table 4 Percentage of women with pregnancies resultıng in fetal loss with and without terminations of pregnancy but since there were fewer women with stillbirths than with miscarriages the confidence intervals were wider For all subtypes of thrombophilia the odds ratio for stillbirths exceeded that for miscarriages Agan, we found no indication of an excess risk of miscarriage in carriers of factor V Leiden However, an increased risk of stillbirth in carners of factor $V$ Leiden does remain possible, although the confidence interval of the odds ratio was wide $(20$ [0 5-7 7]) The odds ratio for stillbirth was higher for all other subtypes of thrombophlia than for factor $V$ Leiden and again highest in those with combined defects

\section{Termination of pregnancy}

$158 \%$ of all the thrombophilic patients who had been pregnant had had at least one induced termination of pregnancy compared with $61 \%$ of the control group $\left(\mathrm{p}<0001, \chi^{\prime}\right.$ test, odds ratio $29\left[\begin{array}{ll}1 & 8-46])\end{array}\right.$ frequency of pregnancy terminations compared with the control group was seen in all the thrombophlic subgroups (table 4) Since these observations could have been influenced by differences between participating centres, the data were reanalysed for each centre In nine of the 11 centres, terminations were more frequent among thrombophlic women than among controls

\section{Influence of paternal thrombophil/a}

Many female partners of men with known thrombophilia have been enrolled in the EPCOT study control group Since these thrombophilic disorders are transmitted with an autosomal dominant pattern, we investigated the pregnancy outcome in the 311 control women who had been pregnant and were partners of men with thrombophila We compared their results with those for 84 control women who had been pregnant and whose partners had no known thrombophulic defect There was no difference in the number of pregnancies or fetal losses between these two groups (data not shown)

\section{Discussion}

In this cross-sectional, multicentre study we found an increased risk of fetal loss in women with heritable deficiencies of antithrombin, protein $C$, or protein $S$ The risks were greatest for women with antithrombin deficiency and for those with combined defects

Although the increased risk of fetal loss was found for both miscarriage and stillbirth, analysed jointly and separately, the effect of thrombophilia was especially pronounced for stillbirths This finding is not unexpected miscarriage is a common event with many possible causes, so positive identification of individual causative factors is difficult, whereas stillbirth is a much rarer event and strong risk factors are more readily identifiable Since our study dealt only with known or confirmed pregnancies, no conclusions can be drawn on the possibility of an effect of thrombophilia on very early fetal loss

No increased risk of tetal loss was evident in women with factor V Leiden For this group, although there was no excess of miscarriages, our results do suggest the possibility of an increased risk of stillbirth We can, however, conclude that the risk of total tetal loss is less than that of the other thrombophilic groups

An increased frequency of pregnancy termmations among women with all types of thrombophnlis, including factor V Leiden, was tound in nine of the 11 participating centres Overall, proportionately more women wh tactor 
$V$ Leiden than women in the other groups had had abortions This tactor may have influenced the number of observed spontaneous fetal losses in these women We did not include these data in our analysis of fetal loss in thrombophilic women, since we believe that they relate to maternal rather than to fetal conditions We cannot identify the reasons for the increased number of pregnancy terminations but speculate that decisions to terminate pregnancy might have been influenced by previous episodes of venous thromboembolism, occurring elther during pregnancy or in association with oral-contraceptive use Conception durng treatment with coumarins might also have been a reason for termination

Since we report on miscarnage and fetal loss assessed retrospectively at the beginning of follow-up, we must consider the possibility of recall bias-ie, the tendency for patients to recall past events more readily than do controls A well-known example of recall bias is that mothers of newborn infants with birth defects are much better able to remember minor illnesses or drugs they took during pregnancy than are mothers of healthy babies We do not think that recall bias is likely to be important in our studv, since in this setting thrombophilia is the minor event, and this diagnosis would be unlikely to make more women remember miscarriage The possibility that the diagnosis would affect the memory of a fetal loss occurring after 28 weeks of gestation is inconcervable

The control group consisted of partners of thrombophilic men and acquaintances of thrombophilic individuals The inclusion of the latter type of controls might theoretically lead to cases and controls being too much alike, which would lead to biased estimates However, since only a small proportion of controls were acquaintances of patients in this cohort, this bias can have had only a slight effect If present, this bias would lead to an underestimate of the difference between cases and controls - thus it cannot explain the higher risk of fetal loss observed in the patients Most of the controls were partners of thrombophilic men We do not think their inclusion introduced a bias, since the possibility that women who choose thrombophilic men as their partners have an intrinsically lower risk of fetal loss is extremely unlikely The frequencv of fetal loss in the control group was similar to that in the general population' Because of the composition of the control group, we were able to investrgate the effect of paternal thrombophilia on fetal loss, no effect was found Since this study deals with genetic abnormalities, confounding bias is unlikely to be present

In view of the well-established relation between the thrombophilic disorders and venous thromboembolism, and the increased thrombotic risk in people with combined defects, the causal mechanism seems likely to involve imparred placental development and function due to a compromised rascular support system A similar mechanism has been proposed for the increased risk of fetal loss associated with the presence of antibodies directed against phospholipids Similar mechanisms for increased fetal loss to those reported here may operate in women with those antibodies, the thrombotic risk in such people has been attributed, at least partly, to disturbances of the protein C protein S pathway" This view is strengthened by evidence from an anmal model of the importance of that pathway for successtul prignancy outcomc
The greatly increased risk of stillbirth in womun with deficiencies of antithrombin, protein $C$, and protein $S$ strongly suggests the possibility of uteroplacental insufficiency as a causative factor Another possibility is fetal thrombosis In the group of patients some of the women are likely to have partners with unidentified thrombophilia, and the fetus could then inherit genes for familial thrombophilia from both parents and be at increased risk of venous thromboembolism by virtue of having combined gene defects, or homozvgosiry for factor $\checkmark$ Leiden

The physiological mechanisms, including the contribution of paternal genes, for implantation and placental and fetal development are poorly understood Our results clearly indicate that the familial thrombotic disorders described here are not associated with female infertility We also provide evidence that in the context of genetic thrombophilic disorders, the increased fetal losses relate to maternal and not paternal abnormalitres

The demonstration of increased fetal losses in women with familial thrombophilia, and especially in those with combined defects or isolated deficiencies of antithrombin, protein $\mathrm{C}$, or protein $\mathrm{S}$, has important therapeutic implications and provides a rationale for clinical trials of thromboprophylaxis for affected women with recurrent fetal loss We must emphasise, however, that although we have shown a significant difference in pregnancy outcome between women with coagulation-inhibitor deficiencies and controls, the probability of a favourable pregnancy outcome is good

The study was supported by BIOMED II grant no BMHI CT94 $1>65$ (coordinator T R Rosendaal)

We thank A Altes, M J Gallego, I C Souto (Barcelona), R Blag1 $O$ Palaren (Bologna), E Avgoren-Pursun, $\&$ Schieber (Frankfurt am Vain), $\mathrm{N} L$ Walker (Glasgow), R Lensen, H H ran Boven (Lerden), K Frıck S Lethagen (Malmo), C Berry (Sheffield) S hoder (Vienna), P Arcier1 (Rome), and M H Horellou (Paris), for therr contributions to the studs

\section{References}

1 Dihlback $B$, Carisson $M$ Svensson PJ Familin thrombophila due to a previously unrecognised mechamism characterised br poor anticoagulant response to activated protein $\mathrm{C}$ prediction of a cofactor to activated proten C Proc Natl 4c al Sul LS 1 1993, 90 1004-08

2 Koster $T$, Rosendaal FR, de Ronde $H$ Briet $E$ Vandenbrouche JP Bertina RM Venous thrombosis due to poor inticoagulant response to activated protein C Luden Thrombophila Study Lancet 1993342 150306

3 Bcruna RM, Kouleman RPC Koster T at il Vutation in blood congulation factor $\mathrm{V}$ associated with resistinue to ictivated protun $\mathrm{C}$ Naturi 1994, $36964-67$

4 Rces DC, Cox M, Clcgg JB World distribution of factor V Luden Lancet $1995,346 \quad 1133-34$

5 Stırrat GM Recurrent miscarriage I detimition and cpidemolorv Lancet 1990, 336 673-75

6 Koulcman RPC, Rutsma PH fllin urt CF Bertma RM Activated piotcin $C$ resistance as an addition il rish tictor for thrombosis in protun C deficient tamlics Bloot 1094 S+ 103135

7 Infontc Ricvard C David M Guthır R Rn ird GE Lupu inticoagulants, anticardiolipin untrbodics ind tet nl loss $N \mathrm{Fn} / \mathrm{f}$ licd $1991,325 \quad 106366$

8 Milia RG Kitchen S, Grcaves 11 Prcston 11 Inhibition of lctul ated protcin $C$ and its cotactor protum $S$ br intephospholiptd intiborics Bry ITacmatol $199076 \quad 10107$

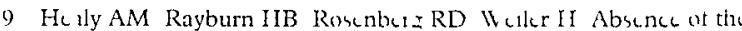
bloodclotting regul itor thrombomodulin c uses cmbronk keth thits in

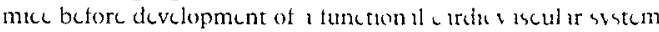
Pue Natl Acad Sa CSA 199592 bo $>$ b

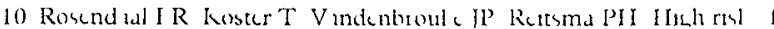

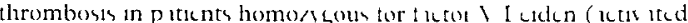

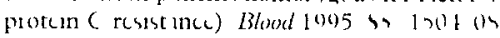

